Motrivivência Ano XXII, No 34, P. 12-24 Jun./2010

DOI:10.5007/2175-8042.2010n34p12

\title{
DOS CONSUMOS CULTURAIS AOS USOS DAS MÍDIAS E TECNOLOGIAS NA PRÁTICA DOCENTE ${ }^{1}$
}

Monica Fantin²

\footnotetext{
Resumo

O artigo trata de alguns resultados de uma pesquisa realizada com professores de diversas áreas de conhecimento do ensino fundamental a respeito dos consumos culturais e dos usos das mídias na docência. Refletindo sobre como as tecnologias estão presentes na vida pessoal e profissional dos professores e sobre o que eles fazem no seu tempo livre, o texto discute a necessidade de pensar em uma outra idéia de escola e da relação entre educação, cultura, mídia e tecnologias da informação e comunicação. Análises

\begin{abstract}
This article present some aspects to think about the uses of media for teachers and the cultural consumption based on analysis of data collect from research. Reflecting on how the technologies are present in personal and professional lives of teachers and what they do in your free time, this text discusses the need to think of another idea of school and the relationship between education, culture, media and technology. The research looks at the
\end{abstract}

1 Este artigo é uma adaptação do texto aceito pela ANPED SUL 2010.

2 Doutora em Educação, Professora do Departamento de Metodologia do Ensino, MEN, e do Programa de Pós-graduação em Educação, PPGE, da Universidade Federal de Santa Catarina, UFSC. Coordenadora do Grupo de Pesquisa Núcleo Infância, Comunicação e Arte, NICA- UFSC/CNPq tem pesquisado temas sobre crianças, mídia, cultura e formação de professores no campo da mídia-educação. Atualmente é Coordenadora do Curso de Pedagogia da UFSC.

Contato: mfantin@terra.com.br.
} 
dos dados da pesquisa apontam indícios de que uma transformação está em curso no que diz respeito à presença das tecnologias e dos artefatos de mídia na escola e sugerem, a partir da interface das dimensões de uso pessoal e profissional, algumas categorias e perfis de uso das tecnologias na prática docente.

Palavras-chave: práticas culturais; uso das mídias e tecnologias, formação, mídia-educação level of insertion of teachers into the technologies, and reflects about the change that the presence of technologies and media in the school promoted suggesting some profiles and categories of use of technology in teaching.

Key words: cultural practices, use of media and technologies, teachers, media education

\section{A escola e a cultura digital}

As novas formas de intermedialidade propiciadas pela chamada "web 2.0" estão revolucionando as práticas individuais e sociais das pessoas, sobretudo de crianças e adolescentes. A facilidade de uso, a oportunidade de interatividade, e a possibilidade de autoria e sociabilidade são algumas características dessas ferramentas que a cultura digital propicia e tais práticas demandam novas pesquisas e reflexões. Tais práticas situam-se entre múltiplas redes sociais que modificam o papel do usuário, cada vez menos simples leitor e cada vez mais autor dos seus conteúdos, e isso remete à reflexão sobre as possibilidades de intervenção educativa na construção de uma cidadania digital, diz Rivoltella (2006).

A portabilidade e a conectividade dessas novas formas permitem maior autonomia em relação aos consumos midiáticos, e a interatividade provocada pela cultura digital promove outras práticas de consumo. Se em relação às mídias tradicionais o problema que se colocava à educação era o de evitar o consumo passivo, hoje com a Internet e os celulares de "última geração" a questão que se coloca é a de educar não só para o consumo responsável mas para uma produção responsável. Através da interatividade que tais mídias propiciam, a comunicação acontece com pessoas e não só com conteúdos, e as pessoas não são mais apenas destinatários de informações, mas produtoras e autoras de conteúdos disponíveis a outros usuários. E essas práticas culturais devem ser discutidas na escola.

Diante das inúmeras desigualdades em relação às barreiras que separam os excluídos do acesso 
às tecnologias, a distância entre os que têm e os que não têm acesso ao acervo da cultura propiciado pelas mídias pode ser pensada em uma perspectiva de mediação cultural da inclusão digital. As diferentes formas de mediação podem ser vistas como possibilidade de transcender os limites utilitaristas e o acesso meramente operacional às máquinas e aos programas, implicando uma inclusão que seja também social, cultural e política.

Nesta perspectiva, a escola e os professores não podem deixar de considerar que mesmo em condições adversas, crianças e jovens acessam as tecnologias, seja nas lan-houses ou noutros espaços sociais, o que sugere a importância da mediação de tais relações em contextos formativos, inclusive para desmistificar o caráter fetichizante que envolve certos usos a fim de "politizar as tecnologias", como diz Santos (2003)

Refletir sobre o sentido do acesso, da análise (interpretação e reflexão), da avaliação e da criação, implica pensar nas possibilidades de uso das tecnologias e do letramento digital entendido como media literacy, como condição de cidadania "real e virtual". Em contextos socioculturais em que nem a leitura e a escrita são apropriadas - o que em alguns casos sugere uma passagem da cultura oral para a digital -, o desafio é ainda maior, e isso remete à discussão de conceitos a respeito das multiliteracies (FANTIN, 2008 A) entendida como leitura, escrita, compreensão (análise-interpretaçãoreflexão) e produção de diversos tipos de texto em todas as linguagens (escrita, audiovisual, musical, eletrônica, midiática, digital, etc.).

Analisando como algumas mídias têm sido incorporadas nas práticas pedagógicas, é possível identificar como as escolas estão lidando com as mudanças provocadas pelas Tecnologias de Informação e Comunicação (TIC). A complexidade que envolve a presença e o uso das tecnologias nas práticas educativas precisa estar articulada não só a uma reconfiguração da escola e seus espaços, mas sobretudo à programas de formação inicial e continuada que discutam o novo perfil profissional do educador nos cenários atuais, principalmente no que diz respeito em sua relação com a cultura, mais especificamente com as mídias e tecnologias.

Tal processo está longe de ser uniforme, e é permeado por variáveis regulam as possibilidades de acesso e participação aos bens culturais. Nesse sentido, a mídiaeducação pode contribuir não apenas para modificar a imagem e credibilidade da escola como para recuperar a legitimidade de seus saberes indo além dos discursos 
que apostam na renovação, inovação tecnológica e incorporação das TIC na escola. Tais ações só fazem sentido se significarem uma transformação da escola e da educação em uma perspectiva cultural articulada com a perspectiva política, econômica e social.

Entre as possibilidades de transformação da escola a partir das dimensões tecnológicas, organizativas e simbólicas, a abordagem culturalista ("mídia-cultura") de Jacquinot (apud RIVOLTELLA, 2006, p.245), reconhece na mídia uma relação estrutural com a dimensão política. A esse respeito, Silverstone argumenta que tanto a política quanto a mídia devem ser entendidas como pensamento e prática, e afirma que "estudamos a mídia porque precisamos compreender como ela contribui para o exercício do poder na sociedade tardo-moderna, tanto dentro como fora do processo político estabelecido" (2005, p.283).

Tais relações aproximamse da idéia de Escola Estação Cultura (FANTIN, 2008) e de um entendimento do que hoje poderíamos chamar de Escola 2.0, ou seja, uma escola que capaz de lidar com as ferramentas do Web 2.0 de forma crítica e criativa. Isso quer dizer uma escola em que professores e estudantes usam as tecnologias de forma reflexiva e produtiva no coti- diano das atividades escolares; uma escola em que as atividades com as mídias não sejam só de leitura, mas de produção; uma escola que aproveita as potencialidades dos blogs, dos celulares, dos instrumentos do social network e que atua também na perspectiva da apropriação da digital literacy. Essa Escola Estação Cultura quer dizer também uma atualização do núcleo válido da escola tradicional no sentido de recuperar o conhecimento clássico para trabalhar com o contemporâneo, com o conhecimento autoral e colaborativo propiciado pela cultura digital, na perspectiva de produção compartilhada de conhecimentos e da participação responsável na paisagem da cultura.

Foi esse horizonte de escola que inspirou a pesquisa com os professores.

\section{A pesquisa e sua aborda- gem metodológica}

O ponto de partida para pensar alguns aspectos da formação dos professores como possibilidade de mediações culturais situa-se no campo da mídia-educação, aqui entendida como possibilidade de educar para/sobre as mídias, com as mídias e através das mídias, a partir de uma abordagem crítica, instrumental e expressivo-produtiva. Esta perspectiva de midia-educação 
implica uma postura "crítica e criadora" de capacidades comunicativas, expressivas e relacionais para avaliar ética e esteticamente o que está sendo oferecido pelas mídias, para interagir significativamente com suas produções culturais, para produzir mídias e também para educar para a cidadania.

Considerando que o saber está em toda parte e não só na escola, nos livros e no professor, uma formação cultural de professores envolve um acervo imagético, literário, artístico, musical das mais diversas produções culturais e uma relação significativa com as tecnologias. Dessa forma buscamos repensar a formação de professores redimensionando os usos das mídias e ampliando a apropriação dos espaços de cultura buscando a diversidade e a abertura de fronteiras que o mundo da comunicação propicia.

Com tais pressupostos, realizamos uma pesquisa em parceria entre a Universidade Federal de Santa Catarina (UFSC) e a Università Cattolica del Sacro di Milano (UCSC), coordenada respectivamente, pelos professores Monica Fantin e Pier Cesare Rivoltella, com o objetivo de fazer um mapeamento inicial sobre os consumos culturais e os usos das mídias por professores do Ensino Fundamental da Rede Pública Municipal de Florianópolis e de Milão. Afinal, em um momen- to em que se discute a reforma curricular em diversos cursos de licenciaturas em nosso país, a investigação pode levantar subsídios para pensar uma formação docente mais sintonizada com os desafios da sociedade contemporânea.

Com o objetivo de identificar os consumos culturais e usos das mídias pelos professores do ensino fundamental e refletir sobre a presença das mídias e tecnologias na produção de conhecimentos e na vida pessoal e profissional, a pesquisa foi realizada em dois contextos socioculturais diferentes. Desenvolvida em parceria entre duas universidades, a investigação considera as especificidades locais de cada contexto e busca elementos para refletir sobre as implicações político-pedagógicas para a formação de professores. Neste texto, apresentamos apenas os dados analisados em apenas um contexto da pesquisa, o de Florianópolis.

A análise preliminar de alguns dados locais sugere que os consumos culturais dos professores estão cada vez mais restritos aos usos domésticos e que é crescente a disponibilidade e o acesso às tecnologias na escola. Junto às possibilidades de boas práticas, a pesquisa aponta ainda que há muitas dificuldades a serem superadas e que precisam ser contempladas na formação de professores. 


\section{Percurso metodológico}

Diversas questões relacionadas à vida escolar só podem ser abordadas em termos de complexidade, reflexo de relações, sistema de valores e diferentes compreensões sobre o que deve ser a escola. Quando estudamos tal complexidade na perspectiva de uma pesquisa, sabemos que corremos riscos de reduções e de limitações e que muitos conteúdos da pesquisa são reflexos das visões de quem a desenvolve. E isso nos coloca diante da necessidade de redirecionar as vozes em busca de diferentes sujeitos que participam da pesquisa, como crianças, jovens e professores. Nessa pesquisa, buscamos o diálogo com os professores, que foram sujeitos e interlocutores desta reflexão.

Ao investigar os modos específicos em que as mídias adquirem significados na prática pedagógica dos professores faz-se necessário estudar seus usos nos cenários "naturais" onde tal prática se revela. Tal pressuposto nos levou a uma pesquisa qualitativa, em que os usos das mídias e das tecnologias pudessem ser melhor compreendidos se fossem situados no âmbito mais amplo dos consumos culturais dos professores.

No entanto, para fazer um mapeamento inicial dos consumos culturais e dos usos das mídias pelos professores é necessário haver uma articulação entre as abordagens da pesquisa qualitativa e quantitativa. Mesmo sabendo que certas técnicas quantitativas possam ser consideradas desagregadoras por sua natureza, ao isolar certos elementos de ação dos contextos em que ocorrem, estes dados também podem ser significativos (MORLEY; SILVERSTONE, 1993).

Assim, do mapeamento inicial, levantamos dados que geraram interpretações, conceitos, sínteses e propostas a partir das palavras e das ações dos sujeitos da pesquisa, e isso se aproxima da abordagem de pesquisa grounded theory (GOULDING, 2006) traduzida no país como teoria fundamentada em dados. Tal perspectiva metodológica também dialoga com a abordagem do interacionismo simbólico, uma vez que pretendemos entender comportamentos e ações a partir do ponto de vista dos participantes e de suas interpretações em determinadas e complexas interações.

Em uma investigação qualitativa e interpretativa de aspectos da vida dos sujeitos da pesquisa, os comportamentos identificados bem como as ações e as interações a serem estudadas, revelam-se em dados vastos e difusos e sua coleta pode combinar diversos métodos: levantamentos, questionários, entrevistas, grupos focais, estudo de 
caso a serem viabilizados através de fontes primárias e secundárias. Por sua natureza flexível e aberta aos meios de comparação, as categorias de análises foram estruturadas ao longo do percurso como aproximações, sendo difícil defini-las a priori de forma única e objetiva.

Além disso, levando em conta os objetivos da pesquisa interinstitucional realizada em parceria, a integração dos pesquisadores envolveu estudo e discussão em torno das concepções teórico-metodológicas norteadoras da pesquisa em comum e seus encaminhamentos no desenvolvimento da pesquisa. Tais procedimentos foram viabilizados a partir de diversos encontros e reuniões presenciais e on line entre seus coordenadores. Afinal, as tecnologias que nos oferecem meios para aprender e compartilhar, também nos permite organizar atividades construtivas de discussão e troca de idéias. Nesta pesquisa, o uso das capacidades comunicativas da tecnologia, além de ser um dos temas ligados ao objeto da investigação, serviu para apoiar o desenvolvimento dos trabalhos dos coordenadores e participantes de pesquisa. E esse caráter colaborativo foi fundamental para a realização desta investigação.

Como toda pesquisa, iniciamos com estudos teóricos sobre o campo temático e com um levantamento bibliográfico sobre o estado da arte. Como a pesquisa buscou fazer um mapeamento inicial sobre os consumos culturais o uso das mídias pelos professores, a perspectiva metodológica pretendia situar tais comportamentos e as ações a partir do ponto de vista dos participantes e de suas interpretações nas complexas interações que eles estabelecem na vida pessoal e profissional. Assim, identificamos comportamentos, ações e interações com a temática através da aplicação de questionários aos professores.

Em reunião com a equipe do Núcleo de Tecnologia Educacional, NTE, da Rede Municipal de Florianópolis, explicamos os objetivos e a importância de divulgar a pesquisa entre os professores da rede a fim de saber quem estaria interessado em participar da investigação. Este levantamento foi feito pelas coordenadoras das salas informatizadas que anotaram nomes e endereços eletrônicos de cada professor interessado. A partir do retorno recebido neste levantamento, foram escolhidas 5 escolas cujos professores demonstraram maior interesse em participar da pesquisa, totalizando em torno de 80 participantes. Após um contato pessoal com cada diretor das respectivas escolas, iniciamos a etapa de coleta de dados.

Como o questionário foi respondido on line, com uma base 
digital situada na universidade italiana, cada professor recebeu um convite via e-mail para participar da pesquisa, cadastrar-se no sistema e responder ao questionário seguindo as orientações dadas. O questionário on line ficou disponível por dois meses e cerca de 50 professores responderam efetivamente do inicio ao fim. Destes, 40 manifestaram interesse em continuar participando da segunda etapa da pesquisa, que após análise parcial dos dados envolveu entrevistas e grupos focais a fim de qualificar melhor as dificuldades encontradas e as boas práticas desenvolvidas pelos professores.

\section{Alguns resultados}

Pesquisa realizada pela UNESCO (2004) traçou um perfil dos professores brasileiros mostrando que a freqüência a eventos culturais é bastante restrita e que metade dos entrevistados não possui computador em casa nem usa Internet. Este quadro parece ser um pouco diferente em Florianópolis, que apresenta o dobro da média nacional em relação aos domicílios que possuem computador conectado à rede de Internet. No entanto, este número ainda é pequeno e a pesquisa revela que além do pouco consumo cultural também parece haver outras formas e situações de exclusão digital entre os professores.
O perfil dos professores que participaram da pesquisa revela que $84,3 \%$ são mulheres e $15,7 \%$ são homens. A maioria situa-se na faixa etária entre 30 e 40 anos; $80,4 \%$ são professores efetivos e $60,8 \%$ possuem formação escolar com pós-graduação em nível de especialização. Uma análise parcial sobre os consumos culturais e os usos pessoais e profissionais das mídias e tecnologias dos professores que participaram da pesquisa pode ser assim sintetizada:

\section{Consumos culturais e tempo livre}

- Consumos culturais: 100\% assistem a programas de televisão; $45 \%$ dos professores raramente vão ao cinema; 27,5\% raramente lêem livros de literatura; $56 \%$ raramente vão a shows musicais; $53 \%$ raramente vão ao teatro; $56,9 \%$ raramente freqüentam museus e galerias de arte. Mas $70,6 \%$ vão aos centros comerciais, shopping center, pelo menos uma vez por mês.

- Atividades de tempo livre: 92,2\% navegam na Internet; 86,3\% lêem revistas; e $70 \%$ participam de atividades de estudo e formação. Entre outras formas de participação, $51,4 \%$ dizem participar do sindicato e $42,9 \%$ de alguma instituição ou entidade religiosa. 
Acesso, usos e consumos

- Posse de equipamentos: 100\% dos professores que participaram da pesquisa possuem televisão, apareIhos de som e máquinas fotográficas; $95 \%$ possuem computadores conectados à rede de Internet e 96\% possuem celular.

- Consumos televisivos: $74,5 \%$ assistem TV diariamente e os programas preferidos são os noticiários; $43 \%$ destes professores fazem referências aos programas de televisão em sala de aula.

- Uso de DVD: 47\% dos professores assistem a filmes pelo menos uma vez por semana e $75 \%$ deles raramente usam DVD na escola. Quando usado, na maioria das vezes aparece para enriquecer conteúdos curriculares e para análise crítica.

- Acesso e uso do cinema: 49\% raramente freqüentam salas de exibição, raramente comentam os filmes com seus alunos e raramente os levam ao cinema.

- Uso de máquina fotográfica: 100\% costumam fotografar ocasiões especiais, sendo que apenas $12 \%$ dizem nunca ter usado a fotografia na escola.

- Acesso e uso de jornal impresso: $100 \%$ dos professores lêem jornal e $39,2 \%$ diariamente; destes apenas $6 \%$ nunca usaram o jornal na escola;

- Uso do celular: $84 \%$ usam dia- riamente sendo que destes, apenas $16 \%$ dizem ter usado celular em situações de ensino-aprendizagem. - Uso do computador: 74,5\% usam diariamente e destes, a grande maioria usa para preparar materiais didáticos; $86 \%$ dos professores usam o computador com seus alunos e a maioria para atividades de produção de textos.

- Acesso, uso e consumo da Internet: $72,5 \%$ acessam a rede diariamente; $98 \%$ usam para correio eletrônico e $96,1 \%$ para pesquisa. Dos que usam internet, 90,2\% acessam em casa, sendo que $81 \%$ possuem MSN, $78 \%$ possuem endereço no orkut, $21 \%$ possuem blog e $16,7 \%$ possuem página pessoal. $77 \%$ usam a Internet em suas aulas e a maioria como fonte de pesquisa.

- Filmadora, gravador de áudio, videogame e MP3 parecem estar pouco presente na vida dos professores e nas práticas docentes.

\section{Dificuldades encontradas}

- Nas dificuldades mencionadas pelos professores, a pesquisa indica que: $82 \%$ alegam falta de conhecimentos específicos para trabalhar com as mídias e as ferramentas tecnológicas; $74 \%$ indicam falta de infra-estrutura e condições de acesso; $66 \%$ dizem que falta formação inicial e continuada; $48 \%$ indicam falta de tempo para aprender a 
usar; e $22 \%$ assinalam outras dificuldades. Tais dados confirmam a necessidade de formação inicial e continuada, justificando não só a importância desta pesquisa, mas a necessidade de se elaborar e viabilizar propostas a esse respeito.

\section{Boas práticas}

- Diversas experiências com mídias e tecnologias na escola foram mencionadas na prática pedagógica dos professores com seus alunos, tais como: produção de audiovisual; animação; web quest; produção e exposição fotográfica; web rádio; construção de blogs; registros com celulares; pesquisas orientadas na Internet; produção e socialização de textos em diversas linguagens; conversas sobre Internet problematizando o sentido dos riscos e/ ou potencialidades e a questão de autoria e responsabilidade; mudança nas formas de ver as produções dos alunos; uso de tecnologias e programas específicos para inclusão de crianças com deficiências; uso de redes sociais para comunicar com alunos; trabalhos interdisciplinares entre professor de sala, professor de educação física, biblioteca e sala informatizada; motivação e participação em cursos de formação e oficinas oferecidas pelo Núcleo de Tecnologia Educativa da Secretaria Municipal de Educação.

\section{Mídia e tecnologia na prá- tica docente: para além das dimensões de uso pessoal e profissional}

É freqüente ouvirmos que os professores não possuem um bom capital cultural, que não sabem usar o computador, que não aproveitam as potencialidades que as tecnologias da web 2.0 e as redes sociais oferecem, e que isso os deixariam cada vez mais "atrasados" em relação aos seus alunos, "nativos digitais" (PRENSKI, 2001), sendo que estes estariam a alguns passos à frente, usando os meios eletrônicos e digitais com grande habilidade (NICOLACI-DA-COSTA, 2006). Mas será que é possível generalizar esse discurso?

Como moldura teórica inicial de nossa reflexão, entendemos a dimensão de consumo para além da explicitada por Canclini (2006), considerando o consumo cultural (e/ou consumo midiático) como uma prática cultural através da qual os sujeitos elaboram, transmitem e recebem os conteúdos simbólicos que, em relação às mídias, dizem respeito a atividades de consumo que não sejam somente receptivas. É possível consumir/ser consumidor, elaborar, produzir e transmitir ao mesmo tempo, como também é possível receber e não elaborar, re- 
ceber e elaborar, e construir e transmitir diversos tipos de conteúdos.

Nesta perspectiva, o conceito de consumo envolve outros três conceitos: usos, representações e apropriações. O consumo é feito de uso e as dimensões de uso envolvem lugar, tempo e modos de consumo. Quando descrevemos os usos do consumo das mídias descrevemos substancialmente onde, como e quando ou por quanto tempo se usa. Sendo uma descrição de comportamento, fenomênica, não nos interrogamos sobre os tipos de experiências que aquela atividade produz, apenas descrevemos um uso. No entanto, este uso está sempre acompanhado de representações, imagens e sistemas de atenção que precedem e acompanham os usos. A apropriação, por sua vez, diz respeito à incorporação das mídias e tecnologias no sistema de vida individual e social do sujeito. Assim, quando as mídias fazem parte da vida do sujeito e integram seu sistema de relações sociais junto às pessoas com as quais se relaciona, há uma forma de apropriação.

Neste quadro, a análise dos dados da pesquisa revela uma forte relação entre os consumos culturais e as dimensões de uso, representação e apropriação das mídias pelos professores na prática docente. Um dado inicial a ser considerado, é que a própria escolha metodológica já revela uma interação com as tecnologias, pois os professores que aceitaram participar da pesquisa deveriam ter, no mínimo, um endereço eletrônico, visto que o questionário deveria ser respondido on line. No entanto, o principio educativo da pesquisa também se revelou em instrumento de pertencimento, pois alguns professores que não possuíam e-mail e nem sabiam usar correio eletrônico sentiram-se motivados para aprender a usar, e assim puderam participar como sujeitos da pesquisa.

Em relação aos recursos disponíveis, que coincidem no ambiente doméstico e escolar, os usos revelam que os professores possuem hábitos consolidados de acesso e navegação na web. No entanto, parece haver um fenômeno instigante: ao mesmo tempo em que os ambientes de alta densidade tecnológica coincidem com as preferências de uso da Internet no tempo livre, o mesmo não ocorre em relação a outras práticas culturais, como ir ao cinema, teatro, etc.

Ao mesmo tempo em que se evidencia uma transformação dos hábitos culturais em ambientes de alta densidade tecnológica fazendo com que haja uma interação cada vez maior com as tecnologias no âmbito pessoal, nem sempre isso ocorre no âmbito profissional. No entanto, quando os professores 
incorporam novos hábitos de consumo midiático, em alguns casos isso parece repercutir positivamente no fazer e na prática docente. E ainda que predomine um uso instrumental das mídias na escola, o sentido da apropriação indica uma perspectiva crescente de produção de artefatos midiáticos, sobretudo relacionadas à produção de audiovisual e ao uso de câmeras fotográficas, DVD, computadores e acesso à Internet. Entretanto, ainda não é possível afirmar que esta prática pedagógica seja transformadora, pois quando os professores apontam as dificuldades encontradas no exercício docente, percebe-se que a inclusão digital, apesar de estar fortemente relacionada à posse de equipamentos eletrônicos e digitais, não se reduz a isso e necessita mediações.

Diante desse quadro, o mapeamento sobre os consumos culturais e os usos das mídias pelos professores feito na pesquisa sugere algumas tendências de uso e formas de apropriação. Para interpretá-las, elaboramos uma categorização de possíveis perfis docentes em relação aos usos das mídias: não usuário (aquele que não usa porque não sabe e/ou porque não quer aprender); iniciante (aquele que está começando a usar algumas tecnologias a nível pessoal); praticante (aquele que possui uso consolidado a nível pessoal e um uso profissional ainda limitado a algumas mídias e tecnologias); pioneiro (aquele que possui uso pessoal e profissional especializado em diversas mídias e tecnologias).

A partir da análise das entrevistas, dos grupos focais e do estudo longitudinal, foi possível fazer um cruzamento dos dados sobre os perfis docentes e suas relações com os consumos culturais, verificando as hipóteses de uso das mídias e seu caráter transmissivo, colaborativo, instrumental e crítico-produtivo. Assim chegou-se a uma sistematização articulando tal categorização com as diferentes nuances das formas de uso e apropriação das diferentes mídias e tecnologias e os consumos culturais dos professores no sentido da fruição, instrumentalização, produção e reflexão.

Por fim, é importante ressaltar que a pesquisa não pretende generalizações e que a análise aprofundada em cada contexto possibilita discutir similaridadesdiferenças, aproximações-distanciamentos nos dois contextos investigados. Considerando as variáveis socioeconômicas e culturais condicionantes dos usos será possível refletir sobre as formas de apropriações das mídias e as necessárias mediações na prática docente. Com isso esperamos contribuir com a elaboração de propostas para a formação inicial e 
continuada de professores na perspectiva da mídia-educação a fim de construir uma prática pedagógica mais significativa e sintonizada com os desafios culturais dos cenários contemporâneos.

\section{Referências}

CANCLINI, N. G. Consumidores e Cidadãos: conflitos multiculturais e globalização. $6^{\mathrm{a}}$. ed., Rio de Janeiro: Editora UFRJ, 2006.

FANTIN, M. Do mito de Sísifo ao vôo de Pégaso: as crianças, a formação de professores e a escola estação cultural. In FANTIN, M.; GIRARDELLO, G. Liga, roda, clica: estudos em mídia, infância e cultura. Campinas: Papirus, 2008. . Multiliteracies na escola.

In Revista Comunicação e Sociedade n.13. Braga:Uminho, 2008 A.

A escola e a cultura digital. In anais do XXXII Congresso Brasileiro de Estudos Interdisciplinares da Comunicação, INTERCOM. Curitiba, 2009.

GOULDING, C. Grounded Theory. London: Sage Publications, 2006.

MORLEY, David y SILVERSTONE, Roger. Comunicación y contexto: la perspectiva etnográfica en los sondeos de opinión. In JENSEN, $\mathrm{K}, \mathrm{B}$ e JANKOWSKI, N.W. Metodologias cualitativas de investigacion em comunicacion de masas. Barcelona, Bosch Casa Editorial.

NICOLACI-DA-COSTA, A. M. (org.) Cabeças digitais: o cotidiano na era da informação. Rio de Janeiro: Loyola, 2006.

PRENSKY, M. Digital Natives, Digital Immigrants. In On the Horizon. Bradford: MCB University Press, Vol. 9 No. 5, October 2001.

RIVOLTELLA, P. C. Media education: fondamenti didattici e prospettive di ricerca. Brescia: Editrice La Scuola, 2005.

Screen Generation: gli adolescenti e le prospettive dell'educazione nell'età dei media digitali. Milano:Vita e Pensiero, 2006.

SANTOS, L.G. Politizar as novas tecnologias: o impacto sócioeconômico da informação digital e genética. São Paulo: Ed.34,2003.

UNESCO. O perfil dos professores brasileiros: o que fazem, o que pensam, o que almejam. São Paulo: Moderna, 2004.

Recebido: setembro/2010. Aprovado: outubro/2010. 